\title{
Differing genetic trend estimates from traditional and genomic evaluations of genotyped animals as evidence of preselection bias in US Holsteins
}

\author{
Y. Masuda, ${ }^{* 1}$ P. M. VanRaden, $\dagger$ I. Misztal, ${ }^{*}$ and T. J. Lawlor \\ *Department of Animal and Dairy Science, University of Georgia, Athens 30602 \\ †Animal Genomics and Improvement Laboratory, Agricultural Research Service, USDA, Beltsville, MD 20705-2350 \\ ‡Holstein Association USA Inc., Brattleboro, VT 05301
}

\begin{abstract}
The objective of this study was to compare genetic trends from single-step genomic BLUP (ssGBLUP) and traditional BLUP models for milk production traits of US Holsteins. Phenotypes were 305-d milk, fat, and protein yields from 21,527,040 cows recorded between January 1990 and August 2015. The pedigree file included 29,651,623 animals and was limited to 3 generations back from recorded or genotyped animals. Genotypes for 764,029 animals were used, and analyses were by a 3 -trait repeatability model as used in the US official genetic evaluation. Unknown-parent groups were incorporated into the inverse of a relationship matrix $\left(\mathbf{H}^{-1}\right.$ in ssGBLUP and $\mathbf{A}^{-1}$ in BLUP) with the QP transformation. For ssGBLUP, 18,359 genotyped animals were randomly chosen as core animals to calculate the inverse of the genomic relationship matrix with the APY algorithm. Computations took $6.5 \mathrm{~h}$ and $1.4 \mathrm{~GB}$ of memory for BLUP, and $13 \mathrm{~h}$ and 115 GB of memory for ssGBLUP. For genotyped sires with at least 10 daughters, the average genetic levels for predicted transmitting ability (PTA) and genomic PTA were similar up to 2008, with a higher level for ssGBLUP later (approximately by $36 \mathrm{~kg}$ for milk, 2.1 $\mathrm{kg}$ for fat, and $1.1 \mathrm{~kg}$ for protein for bulls born in 2010). For genotyped cows, the average genetic levels were similar up to 2006, with a higher level for ssGBLUP (approximately by $91 \mathrm{~kg}$ for milk, $3.6 \mathrm{~kg}$ for fat, and $2.7 \mathrm{~kg}$ for protein for cows born in 2012). For all cows, the average levels were slightly higher for ssGBLUP, with much smaller differences than for genotyped cows. Trends for BLUP indicate bias due to genomic preselection for genotyped sires and cows. For official evaluations released in December 2016, traditional PTA had the same trend as multiple-step genomic PTA for both genotyped bulls and cows except for the youngest bulls, who had traditional PTA slightly lower than genomic
\end{abstract}

Received June 8, 2017.

Accepted December 10, 2017

${ }^{1}$ Corresponding author: yutaka@uga.edu
PTA. For genotyped bulls born in recent years, genetic gain for official traditional and genomic evaluations was similar in contrast to ssGBLUP and BLUP differences. Official PTA for cows were adjusted so that the Mendelian sampling variance was comparable with that for bulls, and those adjustments likely removed bias due to genomic preselection from traditional PTA, especially for genotyped cows. The ssGBLUP method seems to account partially for that bias and is computationally suitable for national evaluations.

Key words: genomic evaluation, predicted transmitting ability, single-step method, bias

\section{INTRODUCTION}

Genomic selection has been rapidly adopted by the US dairy industry since genomic PTA (GPTA) were officially published for young bulls in 2009. Bulls are selected based on GPTA before they have a traditional PTA (tradPTA) based on daughter performance records. Genomic selection has had a positive effect on recent genetic gain because of a shortened generation interval from intensive use of young bulls (García-Ruiz et al., 2016; Wiggans et al., 2017). More than 50\% of all AI matings used genotyped young bulls in 2012 (Hutchison et al., 2014), and this percentage increased to $67 \%$ in 2016 (George R. Wiggans, Council on Dairy Cattle Breeding, Bowie, MD, personal communication).

One concern in current genomic selection is the underestimation of tradPTA for young bulls when genomic preselection is not accounted for in the traditional genetic evaluation (Patry and Ducrocq, 2011a,b). A biased tradPTA could lead to inaccurate GPTA because tradPTA is still needed to construct daughter yield deviations (DYD) for the genomic prediction (VanRaden et al., 2009). Such bias could propagate to other countries through Interbull evaluations based on tradPTA (Patry et al., 2013) if the Interbull evaluations are used as an additional source of information for national evaluations.

A simple method to reduce the bias is to blend genomic information with tradPTA (Ducrocq and Liu, 
2009; Mäntysaari and Strandén, 2010; Patry and Ducrocq, 2011a). This is implemented as an extra step after genomic prediction and needs pseudo-phenotypes derived from tradPTA and GPTA. Stoop et al. (2013) implemented a multiple-trait approach to blend DYD with direct genomic values (DGV; Mäntysaari and Strandén, 2010) for Dutch dairy sires. They found that the method was easily applied using an animal-model framework and could partially account for preselection bias. Although the method works, the approach is ad hoc, and bias may remain because of biased pseudophenotypes (VanRaden, 2012).

The single-step genomic BLUP approach (ssGBLUP) calculates GPTA by combining all available phenotypes, pedigree, and genotypes in the same equations and can possibly account for genomic preselection (Aguilar et al., 2010; Patry and Ducrocq, 2011b). Originally ssGBLUP was considered as a method to account for preselection in dairy cattle only with a limited number of genotyped animals because of high computing cost (VanRaden, 2012). Whereas new algorithms to solve ssGBLUP-based equations were suggested (Fernando et al., 2016a,b; Taskinen et al., 2017), recent developments have removed computing limitations of ssGBLUP in dairy cattle with a large number of genotyped animals (Koivula et al., 2015; Masuda et al., 2016; Misztal, 2016; Strandén et al., 2017).

If the downward bias in the traditional evaluation is real, we should observe a higher trend in GPTA from ssGBLUP (ssGPTA) than in tradPTA for recent animals. The main objective of this study was to compare trends of ssGPTA and tradPTA for milk production traits in the US Holstein population. A secondary objective was to compare the recent genetic trend of official GPTA using a multi-step method with corresponding tradPTA.

\section{MATERIALS AND METHODS}

\section{Data}

The initial data set was derived from that used for the official US official genomic evaluation of Holsteins in August 2015 but with foreign data, other breeds, and crossbreds excluded. The initial data set consisted of over 80 million 305-d lactation records each for milk, fat, and yields from 34 million cows and also included 70 million pedigreed animals.

We excluded old phenotype and pedigree information to reduce computing costs and improve convergence. According to Jamrozik and Schaeffer (1991), the use of all available data in genetic evaluation is important if the interest is in estimation of genetic trends over time. In contrast, Mehrabani-Yeganeh et al. (1999) showed that use of the last 2 discrete or 4 overlapping generations had no significant effect on selection response in traditional evaluations in simulated chicken populations. Our interest was a possible difference in estimated genetic gain after 2009 between traditional BLUP and ssGBLUP evaluations. Therefore, only lactation records from cows that calved in or after 1990 were retained, and pedigree information was limited to 3 generations back from cows with lactation records. The final phenotypic data included 21,527,040 cows with 50,970,954 records for milk and fat yields and 50,319,544 records for protein yield. The pedigree data included 29,651,623 animals. Genotypes included 60,671 SNP markers for 764,029 animals. No SNP chip included all those markers; therefore, imputation was used to fill in missing marker genotypes (Wiggans et al., 2017).

\section{Genetic and Genomic Evaluation}

Traditional Evaluation. We calculated tradPTA using the 3-trait animal model described by VanRaden et al. (2007) and VanRaden et al. (2014). Lactation records were pre-corrected for calving age, season, milking frequency, previous days open, and heterogeneous variance. The model included fixed effects for management group, parity by age, and regressions on inbreeding and general heterosis and random effects for breeding value, permanent environment, and herd-by-sire interaction. Multiple-trait equations and variance components from VanRaden et al. (2014) were used for the 3 production traits. Inbreeding coefficients were considered in the inverse of the numerator relationship matrix $\left(\mathbf{A}^{-1}\right)$. Unknown-parent groups (215) were defined by pedigree path, national origin, and birth year.

Mixed-model equations were solved with the BLUP90IOD2 program that implemented the preconditioned conjugate gradient (PCG) method with parallel processing using OpenMP (Tsuruta et al., 2001; OpenMP Architecture Review Board, 2015). Iteration finished when the squared ratio of the Euclidean norm of residual and right-hand-side vectors:

$$
\frac{\|\mathbf{b}-\mathbf{C x}\|^{2}}{\|\mathbf{b}\|^{2}}=\frac{(\mathbf{b}-\mathbf{C x})^{\prime}(\mathbf{b}-\mathbf{C x})}{\mathbf{b}^{\prime} \mathbf{b}},
$$

where $\mathbf{C}$ is the left-hand-side matrix, $\mathbf{b}$ is the righthand-side vector, and $\mathbf{x}$ is the solution in the current iteration, which was less than $10^{-15}$. The same software and convergence criterion were also used in ssGBLUP.

Single-Step Genomic Evaluation. In the singlestep evaluation, the model, genetic parameters, and 
definition of the unknown-parent group were the same as in the traditional evaluation but $\mathbf{A}^{-1}$ was replaced, with $\mathbf{H}^{-1}$ defined as

$$
\mathbf{H}^{-1}=\mathbf{A}^{-1}+\left[\begin{array}{cc}
\mathbf{0} & \mathbf{0} \\
\mathbf{0} & \mathbf{G}_{A P Y}^{-1}-\mathbf{A}_{22}^{-1}
\end{array}\right],
$$

where $\mathbf{G}_{A P Y}^{-1}$ is the inverse of the genomic relationship matrix $(\mathbf{G})$ created with the algorithm of proven and young (Misztal et al., 2014; Misztal, 2016) and $\mathbf{A}_{22}^{-1}$ is the inverse of the numerator relationship matrix for genotyped animals (Aguilar et al., 2010). The matrix $\mathbf{G}_{A P Y}^{-1}$ was calculated based on $\mathbf{G}$ blended with $\mathbf{A}_{22}$ as $0.95 \mathbf{G}+0.05 \mathbf{A}_{22}$, then scaled to satisfy AvgDiag(scaled $\mathbf{G})=\operatorname{AvgDiag}\left(\mathbf{A}_{22}\right)$ and $\operatorname{AvgOff}(\operatorname{scaled} \mathbf{G})=$ $\operatorname{AvgOff}\left(\mathbf{A}_{22}\right)$, where $\operatorname{Avg} \operatorname{Diag}(\mathbf{X})$ and $\operatorname{AvgOff}(\mathbf{X})$ are the averages of diagonal and off-diagonal elements of a square matrix X, respectively (Masuda et al., 2016).

To form $\mathbf{G}_{A P Y}^{-1}$, we randomly chose a core group of genotyped animals. A randomly selected set of core animals has worked well in earlier analyses (Fragomeni et al., 2015; Bradford et al., 2017). Pocrnic et al. (2016) found that the choice of core animals did not affect the accuracy of genomic evaluation as long as their number was equivalent to or larger than the number of largest eigenvalues that explained $98 \%$ of variation in G. In this study, we set the number of core animals to 18,359 , which was determined with the eigenvalues calculated as the squared singular values of the centered marker matrix (say, $\mathbf{Z}$ ) that includes all genotyped animals formed as formed by VanRaden (2008). The matrix $\mathbf{A}_{22}^{-1}$ was not explicitly created, but a product with a vector (e.g., $\mathbf{q}$ and $\mathbf{A}_{22}^{-1} \mathbf{q}$ ) was indirectly calculated in each PCG iteration (Strandén and Mäntysaari, 2014; Masuda et al., 2017). Computational details of $\mathbf{H}^{-1}$ and its use in the PCG algorithm are described by Masuda et al. (2016) and Misztal and Legarra (2017). The unknown-parent groups were included in ssGBLUP via QP transformation (Misztal et al., 2013):

$$
\mathbf{H}^{*}=\mathbf{A}^{*}+\left[\begin{array}{ccc}
\mathbf{0} & \mathbf{0} & \mathbf{0} \\
\mathbf{0} & \mathbf{G}_{A P Y}^{-1}-\mathbf{A}_{22}^{-1} & -\left(\mathbf{G}_{A P Y}^{-1}-\mathbf{A}_{22}^{-1}\right) \mathbf{Q}_{2} \\
\mathbf{0} & -\mathbf{Q}_{2}^{\prime}\left(\mathbf{G}_{A P Y}^{-1}-\mathbf{A}_{22}^{-1}\right) & \mathbf{Q}_{2}^{\prime}\left(\mathbf{G}_{A P Y}^{-1}-\mathbf{A}_{22}^{-1}\right) \mathbf{Q}_{2}
\end{array}\right],
$$

where $\mathbf{A}^{*}$ is $\mathbf{A}^{-1}$ modified with the QP transformation (Quaas, 1988) and $\mathbf{Q}_{2}$ is a matrix assigning genotyped animals to unknown-parent groups. The use of QP transformation in $\mathbf{H}^{-1}$ greatly improves $\mathrm{PCG}$ convergence for ssGBLUP (Matilainen et al., 2016) compared with using QP transformation for $\mathbf{A}^{-1}$ only. In this study, $\left(\mathbf{G}_{A P Y}^{-1}-\mathbf{A}_{22}^{-1}\right) \mathbf{Q}_{2}$ and $\mathbf{Q}_{2}^{\prime}\left(\mathbf{G}_{A P Y}^{-1}-\mathbf{A}_{22}^{-1}\right) \mathbf{Q}_{2}$ were computed and stored as dense matrices in memory before PCG iteration.

\section{Genetic Trends}

For both traditional and single-step genomic evaluations, the genetic base was set to cows with at least 1 lactation record and born in 2005. The tradPTA and ssGPTA were averaged by birth year for a group of animals. Two groups were defined: (1) bulls that have at least 10 daughters with at least 1 lactation record, and (2) cows with at least 1 lactation record. Table 1 shows the numbers of animals used to estimate the genetic trend. Most of the 764,029 genotyped animals were younger and were not included in trend estimation because they did not have lactation records or daughters with lactation records.

In a separate analysis, we separately investigated the annual change in average official GPTA released in December 2016 (msGPTA16) using a multi-step approach (VanRaden et al., 2009). The reference population included 35,445 bulls (including foreign bulls) and 315,582 cows. The official GPTA was calculated based on the traditional PTA (tradPTA16) from the 3-trait model with data used in the official routine genomic evaluation for December 2016. The official genetic base for December 2016 evaluations was cows born in 2010 rather than 2005.

\section{RESULTS AND DISCUSSION}

\section{Computations}

Table 2 shows the numbers of iterations, wall-clock time per iteration, and total computing time for the traditional and single-step evaluations. The single-step method required slightly more iterations than the traditional evaluation. In each PCG round, ssGBLUP averaged $32 \mathrm{~s}$ more than for the traditional evaluation; 29 $\mathrm{s}$ were for computations related to $\mathbf{G}_{A P Y}^{-1}$ and $\mathbf{A}_{22}^{-1}$ and the remaining $3 \mathrm{~s}$ were related to the additional terms for QP transformation. Computations took slightly more than $6 \mathrm{~h}$ and $1.4 \mathrm{~GB}$ of memory for BLUP and $18.5 \mathrm{~h}$ and $115 \mathrm{~GB}$ of memory for ssGBLUP.

In previous studies with ssGBLUP in dairy cattle, a weight on $\mathbf{A}_{22}^{-1}$, say $\omega$, was needed to ensure a good convergence rate and low inflation of GPTA. An optimal $\omega$ varied from 0.7 when inbreeding was considered in $\mathbf{A}_{22}^{-1}$ but ignored in $\mathbf{A}^{-1}$ (Tsuruta et al., 2011; Masuda et al., 2016), to 0.9 when inbreeding was included in both matrices (Masuda et al., 2015). However, PCG required more than 1,000 iterations to converge, and 
Table 1. Number of US Holsteins used for genetic trend estimation in the traditional and single-step evaluations

\begin{tabular}{|c|c|c|c|c|}
\hline \multirow[b]{2}{*}{ Year of birth } & \multicolumn{2}{|c|}{ Bulls $^{1}$} & \multicolumn{2}{|c|}{ Cows $^{2}$} \\
\hline & Genotyped & Nongenotyped & Genotyped & All \\
\hline 2000 & 437 & 2,106 & 261 & 690,451 \\
\hline 2001 & 507 & 2,110 & 392 & 687,038 \\
\hline 2002 & 581 & 2,020 & 461 & 706,462 \\
\hline 2003 & 522 & 2,026 & 693 & 723,757 \\
\hline 2004 & 1,078 & 1,437 & 1,719 & 767,151 \\
\hline 2005 & 1,252 & 1,182 & 2,076 & 862,803 \\
\hline 2006 & 1,401 & 1,120 & 2,703 & 903,386 \\
\hline 2007 & 1,340 & 880 & 3,687 & 927,492 \\
\hline 2008 & 1,190 & 720 & 6,169 & 985,763 \\
\hline 2009 & 1,209 & 482 & 10,502 & $1,039,972$ \\
\hline 2010 & 1,199 & 159 & 18,167 & $1,043,953$ \\
\hline 2011 & 0 & 0 & 32,982 & $1,057,566$ \\
\hline 2012 & 0 & 0 & 47,321 & 969,331 \\
\hline
\end{tabular}

${ }^{1}$ Bulls that had at least 10 daughters with at least 1 record.

${ }^{2}$ Cows with at least 1 record.

sometimes did not converge. After including inbreeding in both matrices and using the QP transformation, the model converged well (i.e., only 15\% more rounds compared with the traditional evaluation). Similar conclusions were reached by Matilainen et al. (2016).

\section{Genetic Trend for Bulls}

Figure 1 shows genetic trends for tradPTA and ssGPTA of genotyped and nongenotyped bulls that had at least 10 daughters with at least 1 record for milk, fat, and protein yields. Evaluations were higher for genotyped bulls than for nongenotyped bulls. Dairy bulls are almost always genotyped in AI breeding programs in the United States (Hutchison et al., 2014). Bulls used in natural service had not been genotyped because no historical DNA was available, but recently many natural-service bulls have been genotyped as calves but not selected for AI use. Larger genetic gain was observed after 2008 for nongenotyped bulls, mainly because of indirect selection on parents' genomic predictions, which became officially available in 2009. The genetic trends for tradPTA and ssGPTA were almost identical for nongenotyped bulls. For genotyped bulls, ssGPTA was higher than tradPTA for all traits. The difference between genetic trends for tradPTA and ssGPTA was constant until 2008, but the 2 trends diverged in 2009 and 2010. Genetic gain in 2010 was higher for ssGPTA by $36 \mathrm{~kg}$ for milk, $2.1 \mathrm{~kg}$ for fat, and $1.1 \mathrm{~kg}$ for protein. Possible explanations for this divergence in the youngest generation are overestimated ssGPTA, underestimated tradPTA, or both.

Table 2. Wall-clock time per iteration, total computing time, and numbers of iterations for preconditioned conjugate gradient (PCG) for traditional and single-step evaluations ${ }^{1}$

\begin{tabular}{lcc}
\hline Computation $^{2}$ & Traditional BLUP & Single-step BLUP \\
\hline Preparation & $\mathrm{N} / \mathrm{A}$ & $6 \mathrm{~h} 53 \mathrm{~min}$ \\
Computation of $\mathbf{G}_{A P Y}^{-1}$ & $\mathrm{~N} / \mathrm{A}$ & 10 \\
Components of $\mathbf{A}_{22}^{-1}(\mathrm{~min})$ & $\mathrm{N} / \mathrm{A}$ & 10 \\
Additional matrices in $\mathbf{H}^{-1}(\mathrm{~min})$ & 9 & 28 \\
Temporary files (min) & $9 \mathrm{~min}$ & $7 \mathrm{~h} 41 \mathrm{~min}$ \\
Subtotal in preparation & & 464 \\
Iteration phase & 402 & 83 \\
$\quad$ No. of iterations & 51 & 13 \\
Time per PCG iteration (s) & $5 \mathrm{~h} 53 \mathrm{~min}$ & $10 \mathrm{~h} 54 \mathrm{~min}$ \\
After processing (min) & $6 \mathrm{~h} 14 \mathrm{~min}$ & $18 \mathrm{~h} 35 \mathrm{~min}$ \\
Subtotal in iterations & &
\end{tabular}

${ }^{1}$ Both evaluations used a 3 -trait model.

${ }^{2}$ Steps for $\mathbf{G}_{A P Y}^{-1}$ (inverse of genomic relationship matrix created with the algorithm of proven and young) and $\mathbf{A}_{22}^{-1}$ (inverse of the numerator relationship matrix for genotyped animals) used 20 computing cores and the remaining steps used 6 cores on the Intel (Santa Clara, CA) Xeon X7560 2.26 GHz processors. N/A = not performed in the traditional BLUP. 

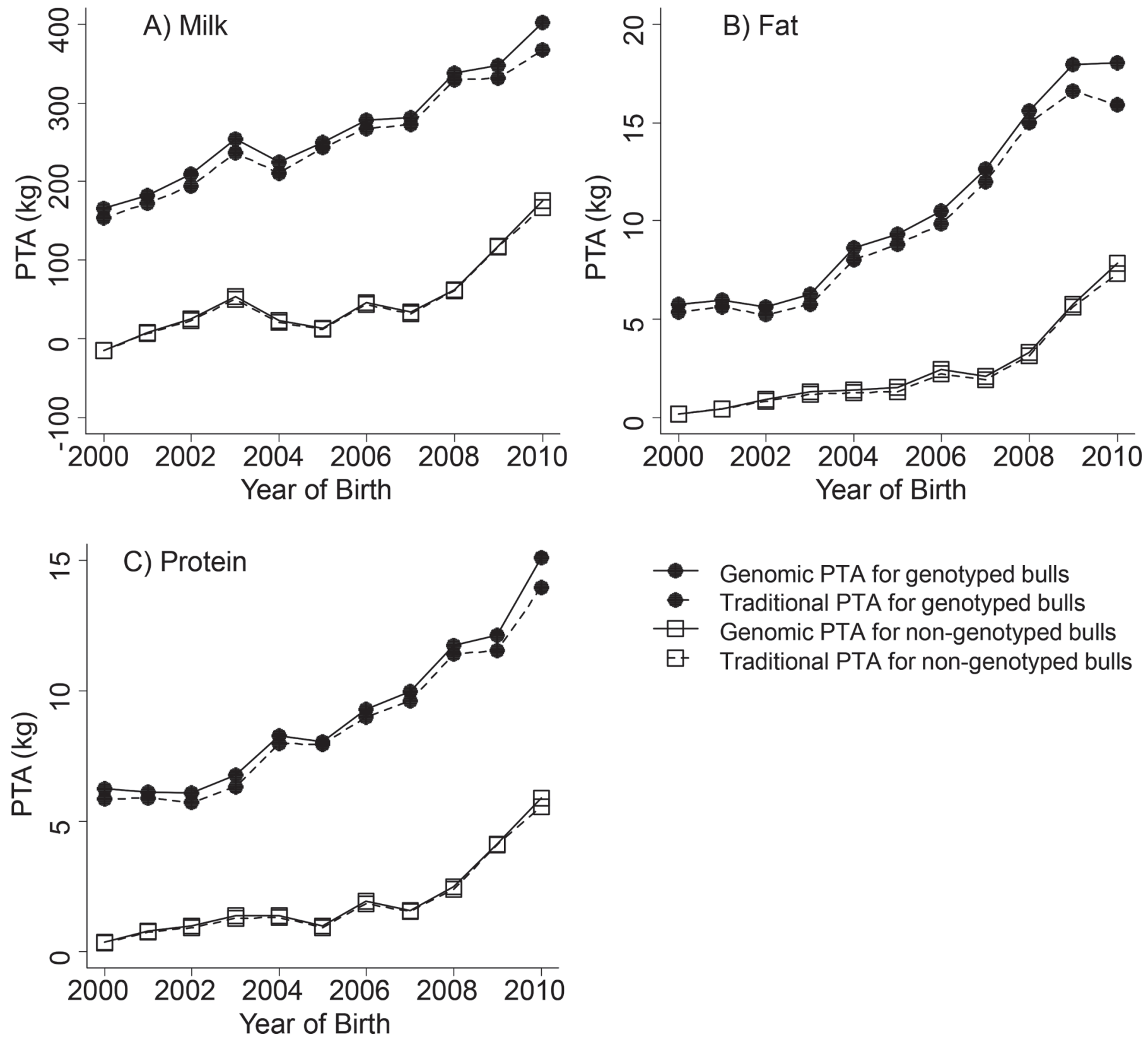

Figure 1. Genetic trends of traditional and genomic PTA for (A) milk yield, (B) fat yield, and (C) protein yield based on data from August 2015 official US genomic evaluations for genotyped and nongenotyped Holstein bulls with at least 10 daughters by bull birth year.

Figure 2 shows genetic trends for msGPTA16 and tradPTA16 for genotyped bulls, and Table 3 shows the genetic gains for genotyped bulls born from 2008 through 2010. For all traits, annual genetic gain was larger for ssGPTA and smaller for tradPTA compared with official gains. Although the official PTA could be underestimated because of the effect of preselection, genetic gains for tradPTA were lower than for tradPTA16 (Table 3 ) and therefore tradPTA is likely to be biased. This underestimation for recent bulls could occur as the result of a limited number of daughters with records, because almost all daughters had only a first-calving record (Nielsen et al., 2015). Under an assumption of underestimated official evaluations, the genetic trend from ssGPTA was reasonable, but this does not prove that ssGPTA is unbiased.

Official genetic trends (Figure 2) did not show the divergence observed after 2009 between tradPTA and ssGPTA. Genetic trends for both tradPTA16 and msGPTA16 were almost the same except in the most 
recent year. The multi-step GPTA used for official evaluations is an index that combines traditional evaluations and DGV using weights based on individual reliability (VanRaden et al., 2009). The GPTA is expected to have the same average as tradPTA if the reliability of tradPTA is high enough. For the youngest bulls, tradPTA apparently is underestimated because of preselection, and its reliability is relatively low. The DGV contributes more in GPTA and partially offsets underestimation of tradPTA.
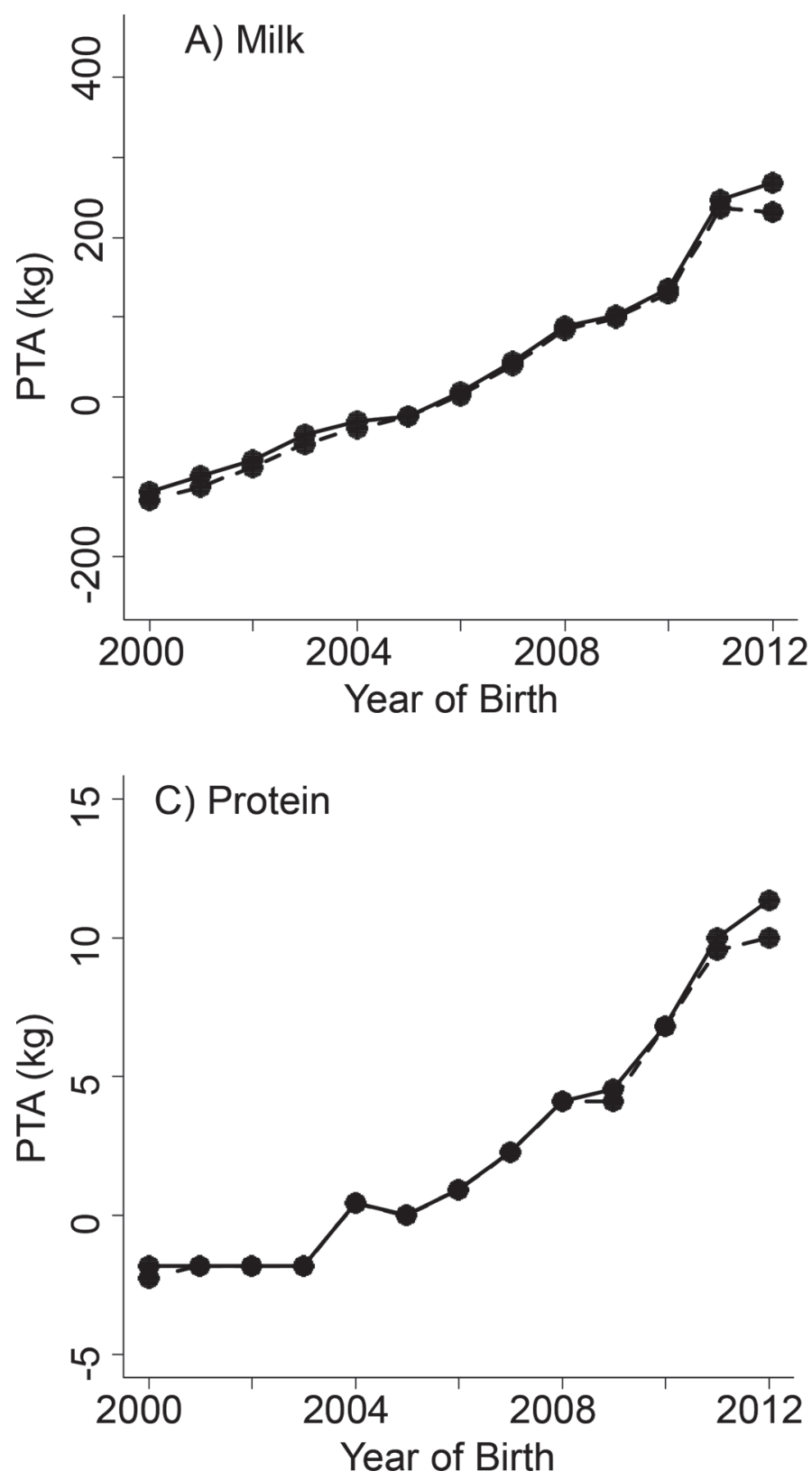

\section{Genetic Trend for Cows}

Figure 3 shows genetic trends for tradPTA and ssGPTA for genotyped and all cows with at least 1 record for milk, fat, and protein yields. The tradPTA and ssGPTA were higher for genotyped cows than for all cows. For all cows, tradPTA and ssGPTA were identical or very similar, and genetic gain per year was relatively constant with only a small divergence in the most recent years (higher ssGPTA).

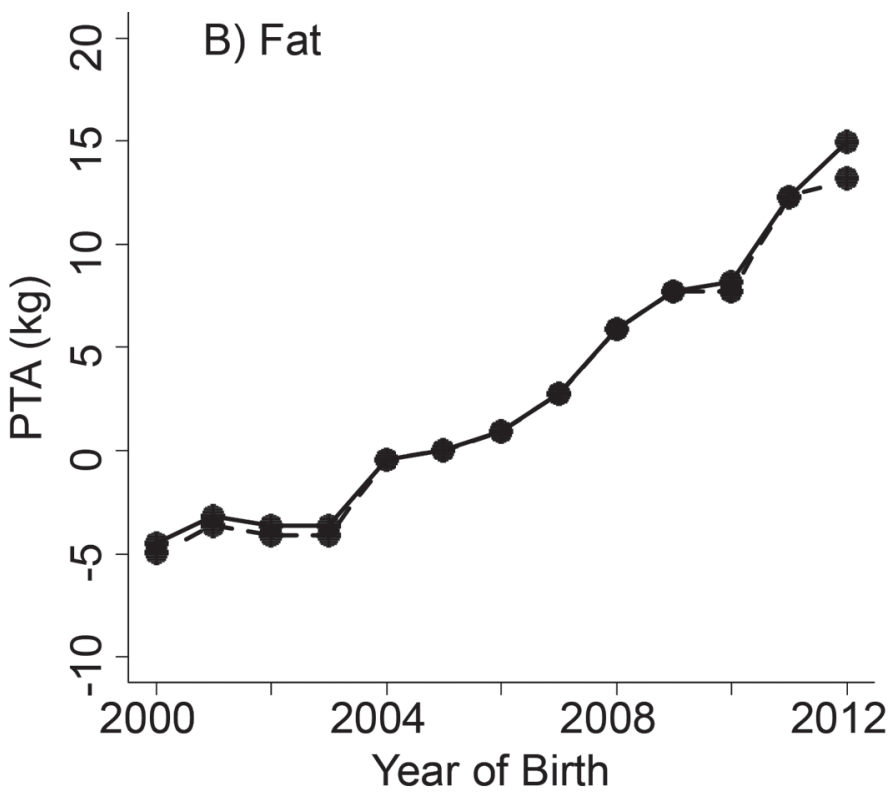

- Official genomic PTA for genotyped bulls - $\quad$ Traditional PTA for genotyped bulls

Figure 2. Genetic trends of December 2016 official US traditional and genomic PTA for (A) milk yield, (B) fat yield, and (C) protein yield for genotyped Holstein bulls with at least 10 daughters by bull birth year. 
In contrast to genotyped bulls, genetic trends for tradPTA and ssGPTA of genotyped cows started diverging around 2007 for all traits before official genomic prediction was implemented. The divergence was larger after 2008, and the difference between tradPTA and ssGPTA was larger than observed for genotyped bulls. In 2012, average ssGPTA was higher than tradPTA by $91 \mathrm{~kg}$ for milk, $3.6 \mathrm{~kg}$ for fat, and $2.7 \mathrm{~kg}$ for protein. Genetic trends for official evaluations of cows were almost identical for tradPTA16 and msGPTA16 (Figure 4). Table 3 shows annual genetic gain for genotyped cows born from 2009 through 2012. As was found for genotyped bulls, estimated gain was slightly higher for ssGPTA and smaller for tradPTA compared with official evaluations. Annual gain found for tradPTA of genotyped cows was close to 0 but did not reflect the whole population. Therefore, tradPTA for genotyped cows likely is underestimated.

Annual genetic means of genotyped cows increased by much less than for the whole population, mainly because of lower selection intensity for cows to be genotyped. At the beginning of genomic testing in 2008 , cows that were selected for genotyping had firstlactation yields that were much higher than those of their contemporaries (Figure 5), especially for cows born from 2000 through 2006. These animals would have had a record and were then selected to be genotyped to determine their genetic merit more accurately. Since 2008, cows that are selected for genotyping have become more representative of the entire population as the price of genotyping decreased and the technology has been adopted by more commercial farms. Fewer than 10,000 cows were genotyped per year for cows born before 2009 (Table 1).

Genomic testing is now a common tool for preselection of females in a herd (Wiggans et al., 2017). The number of genotyped females born in 2012 was 119,572; of those, only 47,321 had lactation records. This preselection will add extra bias to tradPTA for both bulls and cows.

\section{Recent Genetic Gain}

Table 3 shows recent genetic gain for genotyped bulls with at least 10 daughters and for genotyped cows with at least 1 lactation. In general, gains were highest for ssGBLUP (ssGPTA) and lowest for traditional BLUP (tradPTA) with the same data as ssGBLUP. Official genomic (msGPTA16) and nongenomic (tradPTA16) gains were quite similar and in the middle of those for ssGPTA and tradPTA. Differences between the genomic evaluations could be the result of methodology differences. The ssGBLUP method accounts for all information jointly but is sensitive to scaling of the genomic matrix; the multi-step method depends on several assumptions and tuning parameters (e.g., approximation of reliability used for de-regression and weights for blending tradPTA16 with DGV and polygenic effects). Large differences in gains for nongenomic evaluations (tradPTA and tradPTA16) are likely the result of adjustments used in tradPTA16 (VanRaden 2005; Wiggans et al., 2011, 2012) and data differences. Only data from 1990 through 2015 were used to calculate evaluations for this study; official evaluations were based on complete data from 1960 through 2016. The official model adjusts for differences between past and expected future inbreeding depression, which tends to reduce estimated genetic trend (VanRaden, 2005).

Future research could consider uncertain paternity as another potential cause of trend biases. Most genotyped animals have known parents, whereas the

Table 3. Annual genetic gain ${ }^{1}$ for genotyped US Holstein bulls and cows by birth-year period and evaluation method

\begin{tabular}{lllccc}
\hline $\begin{array}{l}\text { Genotyped } \\
\text { animals }^{2}\end{array}$ & Birth years & $\begin{array}{l}\text { Evaluation } \\
\text { method }^{3}\end{array}$ & $\begin{array}{c}\text { Milk } \\
(\mathrm{kg})\end{array}$ & $\begin{array}{c}\text { Fat } \\
(\mathrm{kg})\end{array}$ & $\begin{array}{c}\text { Protein } \\
(\mathrm{kg})\end{array}$ \\
\hline Bulls & $2008-2010$ & ssGPTA & 32 & 1.2 & 1.7 \\
& & tradPTA & 19 & 0.5 & 1.3 \\
& & msGPTA16 & 23 & 1.1 & 1.4 \\
Cows & tradPTA16 & 23 & 0.9 & 1.4 \\
& & ssGPTA & 29 & 1.0 & 1.1 \\
& & tradPTA & 7 & 0.2 & 0.4 \\
& msGPTA16 & 23 & 1.0 & 1.0 \\
\hline
\end{tabular}

${ }^{1}$ Calculated with a slope coefficient from a linear regression of genetic (genomic) evaluation on year of birth.

${ }^{2}$ Bulls that had at least 10 daughters with at least 1 record and cows with at least 1 record.

${ }^{3}$ SSGPTA = genomic PTA with single-step genomic BLUP; tradPTA = traditional PTA with an animal model; msGPTA16 = official multi-step genomic PTA released in December 2016; tradPTA16 = traditional PTA based on data for December 2016 official evaluations. 
numerator relationship matrix may be incorrect for many nongenotyped animals. This could cause differences in estimated trends and EBV between these groups and for bulls with more or fewer genotyped progeny.

We should note that tradPTA16 were used as an input for official genomic prediction. Official PTA of genotyped cows were adjusted to make variance of Mendelian sampling comparable with that for traditional PTA of bulls and nongenotyped cows (Wiggans et al.,
2012). With that adjustment, the trend for tradPTA of genotyped cows was very similar to their trend for DGV and therefore, genomic PTA, too. Unadjusted PTA may be more comparable with tradPTA from this study. For example, annual genetic gain in milk yield for genotyped cows with a record and born from 2009 through 2012 was $24 \mathrm{~kg}$ with the adjustments (tradPTA16, Table 3) but $16 \mathrm{~kg}$ without adjustment (data not shown), which was closer to the $7 \mathrm{~kg}$ estimated for tradPTA (Table 3).
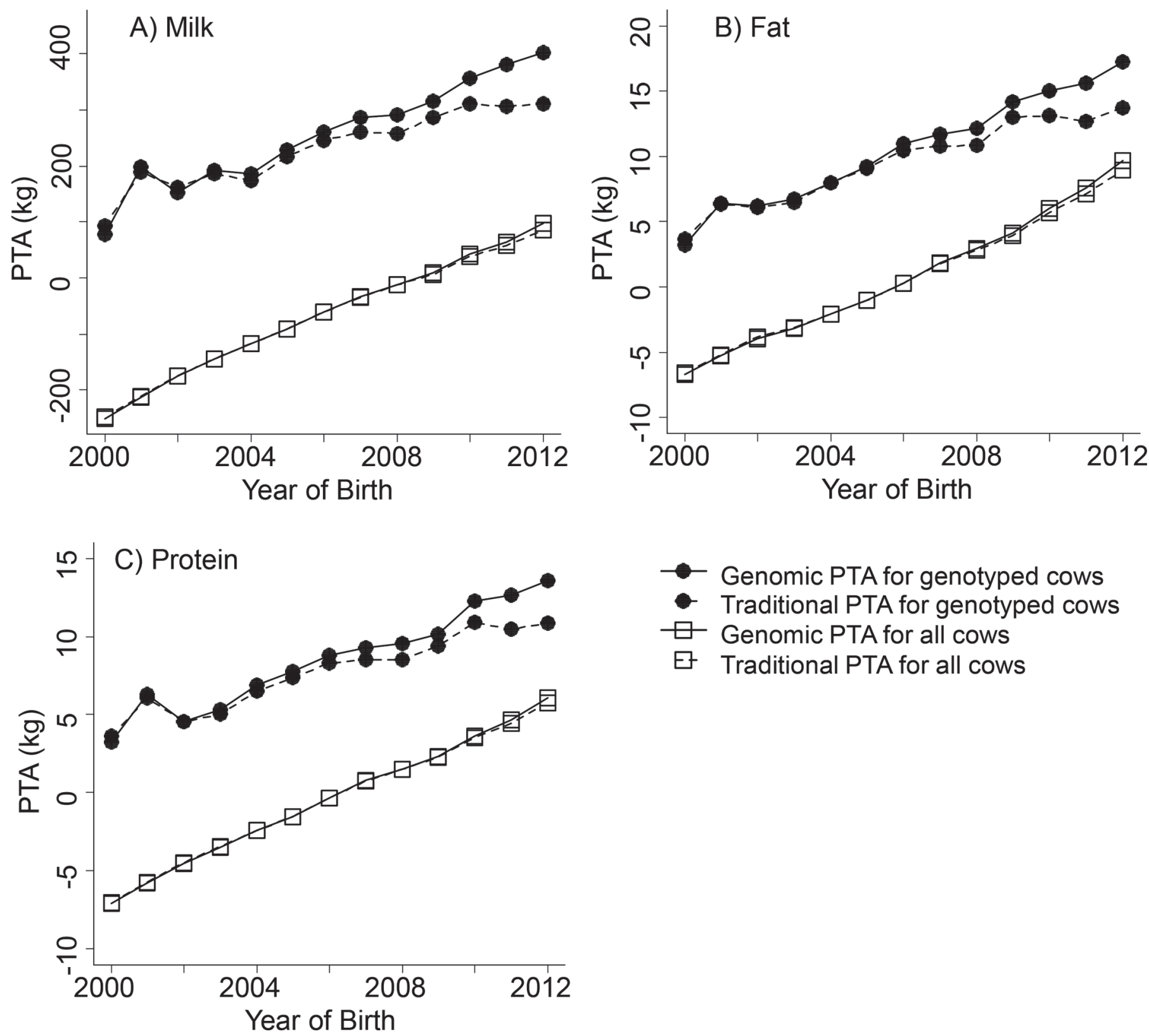

Figure 3. Genetic trends of traditional and genomic PTA for (A) milk yield, (B) fat yield, and (C) protein yield based on data from August 2015 official US genomic evaluations for genotyped and all Holstein cows with at least 1 record by cow birth year. 

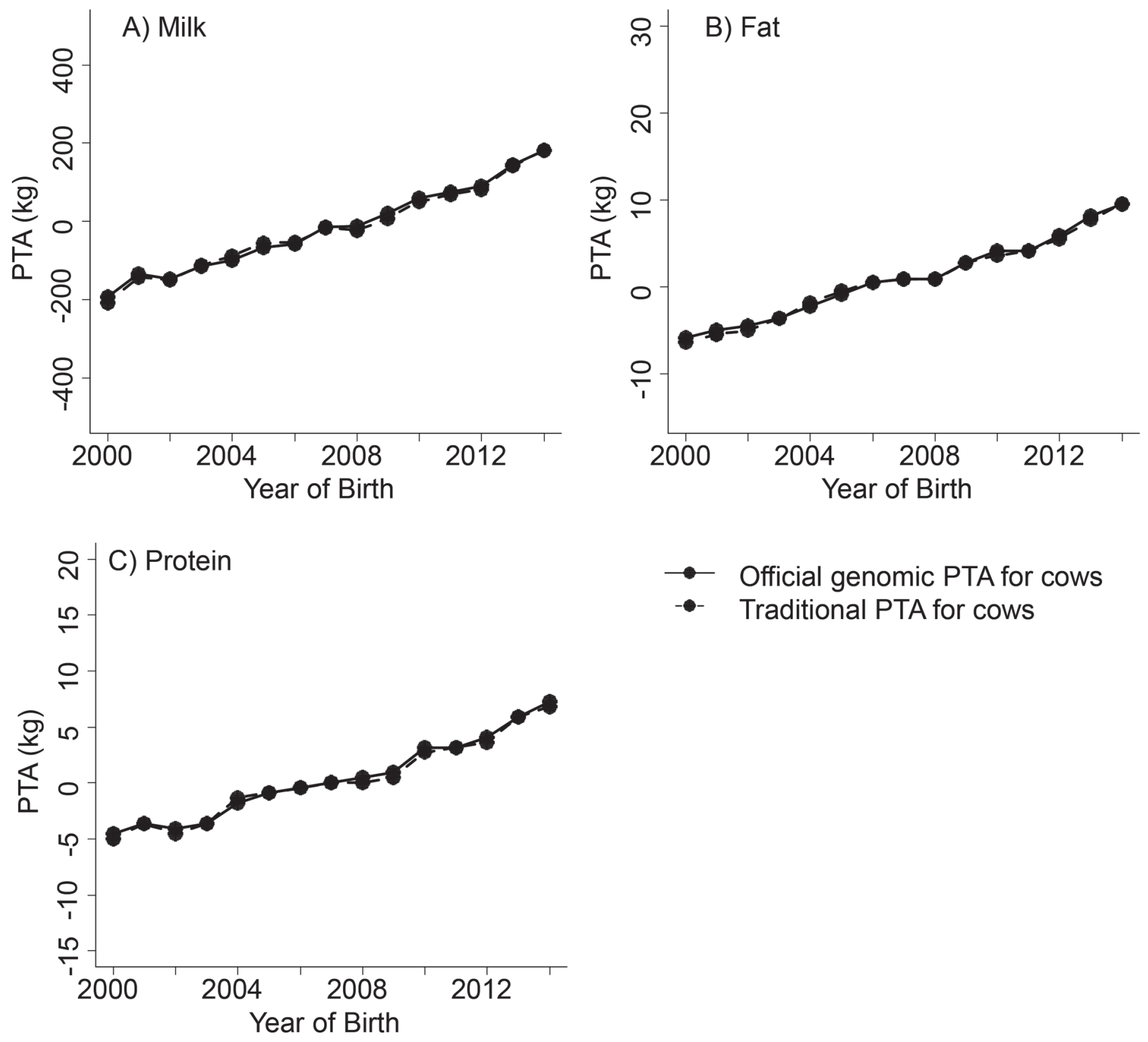

Figure 4. Genetic trends of December 2016 official US traditional and genomic PTA (A) milk yield, (B) fat yield, and (C) protein yield for Holstein cows with at least 1 record by cow birth year.

\section{Differences in Trends Between Genotyped Males and Females}

Differences between ssGPTA and tradPTA for genotyped animals born in 2012 (Figures 1 and 3) were more than twice as large for cows as for bulls. The genotyped cows likely were selected based on genomic predictions with positive Mendelian sampling before their having lactation records. For traditional BLUP, assume that tradPTA $=w_{1} \mathrm{PA}+w_{2} \mathrm{YD}$ for cows with- out phenotyped daughters, where PA is parent average, YD is yield deviation, and $w_{1}$ and $w_{2}$ are appropriate weights (VanRaden and Wiggans, 1991). The genomic superiority of phenotyped cows is confounded with the contemporary-group effect or other nongenetic effects because the numerator relationship matrix does not account for the effect of preselection. Cow YD is lower than the genetic base, and underestimated YD contributes not only to cow PTA and but also to parent PTA. For ssGBLUP, assume that ssGPTA $=w_{1} \mathrm{PA}$ 
$+w_{2} \mathrm{YD}+w_{3} \mathrm{DGV}-w_{4} \mathrm{PI}$, where PI is a subset of PA that is doubly counted in DGV and $w_{1}$ to $w_{4}$ are appropriate weights (VanRaden et al., 2009; Lourenco et al., 2015). The DGV can account for unaccounted Mendelian sampling for genotyped cows. A young cow has fewer observations and phenotyped daughters compared with a bull that has 10 or more daughters with records. For such a cow, less phenotypic information leads to a smaller weight $\left(w_{2}\right)$ on YD, which may not correct tradPTA bias. This is a possible reason why we observed the larger PTA difference between ssGBLUP and BLUP for younger genotyped cows.

For genotyped bulls, ssGPTA $=w_{1} \mathrm{PA}+w_{5} \mathrm{PC}+$ $w_{3} \mathrm{DGV}-w_{4} \mathrm{PI}$, where $\mathrm{PC}$ is progeny contribution from daughters with phenotypes and $w_{5}$ is a weight. With a large number of daughters, PC dominates, and most of the BLUP bias for bulls originates from PC (or equivalently DYD). A genotyped bull has 2 sources for tradPTA bias: its own genomic preselection and the underestimated PC because of pre-selected daughters.
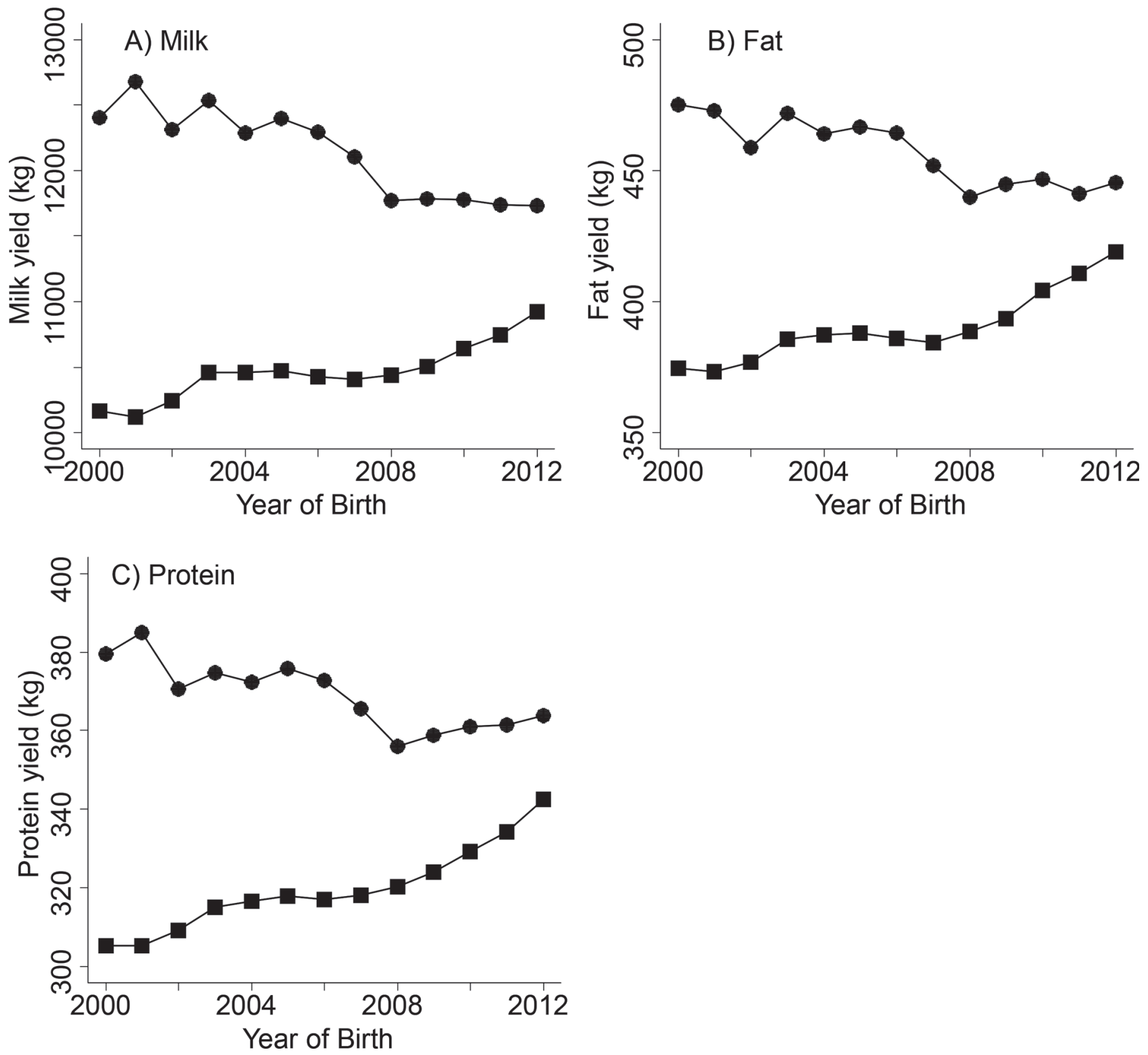

Figure 5. Mean first-lactation yields for (A) milk, (B) fat, and (C) protein by birth year for genotyped ( $)$ and all cows ( 
Biases in tradPTA can be higher for bulls with a larger fraction of genotyped daughters or mates because the Mendelian sampling of their phenotyped progeny and mates is no longer expected to average 0 ; however, recent estimates of those preselection biases are small (VanRaden, 2016). Genomic preselection of the bulls themselves can bias traditional animal models because young bulls are regressed toward PA and their superior Mendelian sampling is ignored (Patry and Ducrocq, 2011b). In the next few years, trend differences may be larger for genotyped bulls. With ssGBLUP, ssGPTA seems not to be underestimated. With BLUP, bias due to a young bull's preselection remains in tradPTA even though the currently underestimated trend for younger bulls approaches the expected trend as the bulls have more nongenotyped daughters. That bias accumulates in the next generation through continued genomic preselection of young bulls. For female genotypes, we expect that ssGPTA has the same genetic gain found for all cows with records as long as all relevant females are included in ssGBLUP. Trend of tradPTA for genotyped cows is unpredictable, but at least, the tradPTA trend will not catch up the trend of ssGPTA and the difference will grow.

For single-step analysis, which used data through August 2015, the youngest genotyped bulls were born in 2010, and they were not necessarily sons of young sires without daughters. The difference between genetic trends for ssGPTA and tradPTA might be more obvious with a recent data set that had more genotyped sons of young bulls. In contrast, the data set included genotyped cows born in more recent years. This may possibly explain the more obvious difference in genetic trends for genotyped cows.

\section{Further Discussion}

This study suggests that tradPTA for daughterproven bulls born in the last generation is likely to be underestimated. If so, the downward bias will be transferred to DYD or de-regressed proofs and that transition will cause problems both nationally and internationally. A multi-step genomic evaluation uses both unbiased DYD from older animals and underestimated DYD from younger animals, and the resulting GPTA could also be underestimated for young bulls. In validation studies with truncated data, genomic predictions for young bulls tended to be inflated [i.e., the slope of the linear regression of DYD or de-regressed proof on prediction (i.e., $b_{1}$ ) was less than 1 (Koivula et al., 2015; Masuda et al., 2016; Wiggans et al., 2017)]. The single-step method should fully account for preselection by including the genomic data but may require additional adjustments to remove other biases that occur with real data.

Patry et al. (2013) concluded that pre-selected young bulls are penalized in international evaluation and that the bias propagates to their relatives and affects their international rankings for all traits. Biases due to genomic preselection in national evaluations should be detected and corrected before the evaluations are sent to the Interbull Centre (Uppsala, Sweden). Adjustment for genomic preselection on the traditional PTA as an additional step in genomic prediction is a realistic solution of the moment because it does not require drastic changes in national and international evaluation systems (Stoop et al., 2013). Single-step GBLUP has been officially implemented in Belgium and the Czech Republic. If ssGPTA (or its de-regressed proof) is sent to the Interbull Centre as a traditional evaluation, the double counting of genomic information may cause an extra bias in ssGPTA because the international evaluations are used as extra information in national evaluations (Šplíchal et al., 2017). Vandenplas and Gengler (2012) and Vandenplas et al. (2014, 2017) suggested methods to integrate international evaluations into national ssGPTA. Further research is needed to examine the use of such methods for large-scale domestic and international data.

Mäntysaari et al. (2017) found DYD biased and therefore validations based on DYD biased. They found validations based on genomic prediction of cow records unbiased. If so, trends based on cows may be more informative than those based on bulls. However, many countries have excluded cows from their reference populations or used adjustments to account for preferential treatment of elite cows (Wiggans et al., 2011). Thus, 2 opposite biases may occur: PA that are too high because of preferential treatment, and progeny that are not credited for being better than PA because of genomic preselection. The latter is expected to be smaller than that estimated by Patry and Ducrocq (2011b) because generations overlap in real data and bulls now have many more progeny, which makes their evaluations less dependent on assumed PA.

\section{CONCLUSIONS}

The ssGBLUP evaluation seems to account for effects of preselection that are not accounted for by traditional BLUP. When applied to national production traits, recent differences in genetic trends between traditional BLUP and ssGBLUP were larger for cows than for bulls. Further studies will determine whether ssGBLUP offers benefits to the dairy industry beyond those from the current multi-step method. 


\section{ACKNOWLEDGMENTS}

The Council of Dairy Cattle Breeding (Bowie, MD) provided phenotype, genotype, and pedigree data for this study. The authors thank John Cole and Melvin Tooker of the Animal Genomics and Improvement Laboratory, Agricultural Research Service, USDA (Beltsville, MD) for preparation of the initial data set and computing facilities. The authors also thank H. Duane Norman of the Council on Dairy Cattle Breeding for manuscript review. The authors acknowledge Suzanne Hubbard of the Animal Genomics and Improvement Laboratory, Agricultural Research Service, USDA (Beltsville, MD) for suggestions largely improving the final manuscript. This research was primarily supported by grants from Holstein Association USA (Brattleboro, VT) and USDA's National Institute of Food and Agriculture (Washington, DC; Agriculture and Food Research Initiative competitive grant 2015-67015-22936). P. M. VanRaden was supported by USDA Agricultural Research Service appropriated project 1245-31000-10100, "Improving Genetic Predictions in Dairy Animals Using Phenotypic and Genomic Information." Helpful comments by 2 anonymous reviewers on earlier drafts of the manuscript are greatly appreciated.

\section{REFERENCES}

Aguilar, I., I. Misztal, D. L. Johnson, A. Legarra, S. Tsuruta, and T. J. Lawlor. 2010. Hot topic: A unified approach to utilize phenotypic, full pedigree, and genomic information for genetic evaluation of Holstein final score. J. Dairy Sci. 93:743-752. https://doi.org/10 .3168/jds.2009-2730.

Bradford, H. L., I. Pocrnić, B. O. Fragomeni, D. A. L. Lourenco, and I. Misztal. 2017. Selection of core animals in the Algorithm for Proven and Young using a simulation model. J. Anim. Breed. Genet. https://doi.org/10.1111/jbg.12276. In press.

Ducrocq, V., and Z. Liu. 2009. Combining genomic and classical information in national BLUP evaluations. Interbull Bull. 40:172-177.

Fernando, R. L., H. Cheng, and D. J. Garrick. 2016a. An efficient exact method to obtain GBLUP and single-step GBLUP when the genomic relationship matrix is singular. Genet. Sel. Evol. 48:80. https://doi.org/10.1186/s12711-016-0260-7.

Fernando, R. L., H. Cheng, B. Golden, and D. J. Garrick. 2016b. Computational strategies for alternative single-step Bayesian regression models with large numbers of genotyped and non-genotyped animals. Genet. Sel. Evol. 48:96. https://doi.org/10.1186/s12711 $-016-0273-2$

Fragomeni, B. O., D. A. L. Lourenco, S. Tsuruta, Y. Masuda, I. Aguilar, A. Legarra, T. J. Lawlor, and I. Misztal. 2015. Hot topic: Use of genomic recursions in single-step genomic best linear unbiased predictor (BLUP) with a large number of genotypes. J. Dairy Sci. 98:4090-4094. https://doi.org/10.3168/jds.2014-9125.

García-Ruiz, A., J. B. Cole, P. M. VanRaden, G. R. Wiggans, F. J. Ruiz-López, and C. P. Van Tassell. 2016. Changes in genetic selection differentials and generation intervals in US Holstein dairy cattle as a result of genomic selection. Proc. Natl. Acad. Sci. USA 113:E3995-E4004. https://doi.org/10.1073/pnas.1519061113.

Hutchison, J. L., J. B. Cole, and D. M. Bickhart. 2014. Short communication: Use of young bulls in the United States. J. Dairy Sci. 97:3213-3220. https://doi.org/10.3168/jds.2013-7525.
Jamrozik, J., and L. R. Schaeffer. 1991. Procedures for updating solutions to animal models as data accumulate. J. Dairy Sci. 74:19932000. https://doi.org/10.3168/jds.S0022-0302(91)78368-9.

Koivula, M., I. Strandén, J. Pösö, G. P. Aamand, and E. A. Mäntysaari. 2015. Single-step genomic evaluation using multitrait random regression model and test-day data. J. Dairy Sci. 98:2775-2784. https://doi.org/10.3168/jds.2014-8975.

Lourenco, D. A. L., B. O. Fragomeni, S. Tsuruta, I. Aguilar, B. Zumbach, R. J. Hawken, A. Legarra, and I. Misztal. 2015. Accuracy of estimated breeding values for males and females with genomic information on males, females, or both: an example on broiler chicken. Genet. Sel. Evol. 47:56. https://doi.org/10.1186/s12711 $-015-0137-1$.

Mäntysaari, E., M. Koivula, G. P. Aamand, and I. Strandén. 2017. Validation of genomic and genetic evaluations. In 2017 Interbull Technical Workshop, February 6-7, 2017, Ljubljana, Slovenia. Accessed May 23, 2017. http://www.interbull.org/static/web/ Mantysaary.pdf.

Mäntysaari, E. A., and I. Strandén. 2010 Use of bivariate EBV-DGV model to combine genomic and conventional breeding value evaluations. In Proceedings of the 9th World Congress on Genetics Applied to Livestock Production. Leipzig (Germany). Aug. 1-6.

Masuda, Y., I. Misztal, A. Legarra, S. Tsuruta, D. A. L. Lourenco, B. O. Fragomeni, and I. Aguilar. 2017. Technical note: Avoiding the direct inversion of the numerator relationship matrix for genotyped animals in single-step genomic best linear unbiased prediction solved with the preconditioned conjugate gradient. J. Anim. Sci. 95:49-52. https://doi.org/10.2527/jas.2016.0699.

Masuda, Y., I. Misztal, S. Tsuruta, A. Legarra, I. Aguilar, D. A. L. Lourenco, B. O. Fragomeni, and T. J. Lawlor. 2016. Implementation of genomic recursions in single-step genomic best linear unbiased predictor for US Holsteins with a large number of genotyped animals. J. Dairy Sci. 99:1968-1974. https://doi.org/10.3168/jds $.2015-10540$.

Masuda, Y., I. Misztal, S. Tsuruta, D. A. L. Lourenco, B. O. Fragomeni, A. Legarra, I. Aguilar, and T. J. Lawlor. 2015. Single-step genomic evaluations with $570 \mathrm{~K}$ genotyped animals in US Holsteins. Interbull Bull. 49:85-89.

Matilainen, K., M. Koivula, I. Strandén, G. P. Aamand, and E. A. Mäntysaari. 2016. Managing genetic groups in single-step genomic evaluations applied on female fertility traits in Nordic Red dairy cattle. Interbull Bull. 50:71-75.

Mehrabani-Yeganeh, H., J. P. Gibson, and L. R. Schaeffer. 1999. Using recent versus complete pedigree data in genetic evaluation of a closed nucleus broiler line. Poult. Sci. 78:937-941. https://doi.org/ $10.1093 / \mathrm{ps} / 78.7 .937$.

Misztal, I. 2016. Inexpensive computation of the inverse of the genomic relationship matrix in populations with small effective population size. Genetics 202:401-409. https://doi.org/10.1534/genetics.115 .182089 .

Misztal, I., and A. Legarra. 2017. Invited review: Efficient computation strategies in genomic selection. Animal 11:731-736. https:// doi.org/10.1017/S1751731116002366.

Misztal, I., A. Legarra, and I. Aguilar. 2014. Using recursion to compute the inverse of the genomic relationship matrix. J. Dairy Sci. 97:3943-3952. https://doi.org/10.3168/jds.2013-7752.

Misztal, I., Z. G. Vitezica, A. Legarra, I. Aguilar, and A. A. Swan. 2013. Unknown-parent groups in single-step genomic evaluation. J. Anim. Breed. Genet. 130:252-258. https://doi.org/10.1111/jbg .12025 .

Nielsen, U. S., J. Pösö, P. Madsen, E. A. Mäntysaari, J. Pedersen, G. $\mathrm{Su}$, and G. P. Aamand. 2015. Effect of genomic pre-selection on the stability of EBVs from traditional BLUP procedure for production traits-A practical illustration. Presentation at 2015 Interbull Technical Workshop and Industry Meeting, February 24-25, 2015, Walsrode, Germany. Accessed May 23, 2017. http://www .interbull.org/static/web/4_3_Nielsen.pdf.

OpenMP Architecture Review Board. 2015. OpenMP application program interface version 4.5. Accessed Nov. 3, 2017. http://www .openmp.org/wp-content/uploads/openmp-4.5.pdf. 
Patry, C., and V. Ducrocq. 2011a. Accounting for genomic pre-selection in national BLUP evaluations in dairy cattle. Genet. Sel. Evol. 43:30. https://doi.org/10.1186/1297-9686-43-30.

Patry, C., and V. Ducrocq. 2011b. Evidence of biases in genetic evaluations due to genomic preselection in dairy cattle. J. Dairy Sci. 94:1011-1020. https://doi.org/10.3168/jds.2010-3804.

Patry, C., H. Jorjani, and V. Ducrocq. 2013. Effects of a national genomic preselection on the international genetic evaluations. J. Dairy Sci. 96:3272-3284. https://doi.org/10.3168/jds.2011-4987.

Pocrnic, I., D. A. L. Lourenco, Y. Masuda, A. Legarra, and I. Misztal. 2016. The dimensionality of genomic information and its effect on genomic prediction. Genetics 203:573-581. https://doi.org/10 .1534 /genetics.116.187013.

Quaas, R. L. 1988. Additive genetic model with groups and relationships. J. Dairy Sci. 71:1338-1345. https://doi.org/10.3168/jds S0022-0302(88)79691-5.

Šplíchal, J., J. Bauer, J. Přibyl, and J. Motyčka. 2017. Implanting MACE values in national single step genomic evaluation. Presentation at 2017 Interbull Technical Workshop, February 6-7, 2017, Ljubljana, Slovenia. Accessed Aug. 18, 2017. http://www.interbull .org/static/web/Splichal.pdf.

Stoop, W. M., H. Eding, M. L. van Pelt, L. C. M. de Haer, and G. de Jong. 2013. Using pseudo-observations to combine genomic and conventional data in the Dutch-Flemish national evaluation. Interbull Bull. 47:106-110.

Strandén, I., and E. A. Mäntysaari. 2014. Comparison of some equivalent equations to solve single-step GBLUP. In Proceedings of the 10th World Congress on Genetics Applied to Livestock Production. Vancouver (Canada). Aug. 17-22, Commun. 069.

Strandén, I., K. Matilainen, G. P. Aamand, and E. A. Mäntysaari. 2017. Solving efficiently large single-step genomic best linear unbiased prediction models. J. Anim. Breed. Genet. 134:264-274. https://doi.org/10.1111/jbg.12257.

Taskinen, M., E. A. Mäntysaari, and I. Strandén. 2017. Single-step SNP-BLUP with on-the-fly imputed genotypes and residual polygenic effects. Genet. Sel. Evol. 49:36 https://doi.org/10.1186/ s12711-017-0310-9.

Tsuruta, S., I. Misztal, I. Aguilar, and T. J. Lawlor. 2011. Multiple-trait genomic evaluation of linear type traits using genomic and phenotypic data in US Holsteins. J. Dairy Sci. 94:4198-4204. https://doi.org/10.3168/jds.2011-4256.

Tsuruta, S., I. Misztal, and I. Stranden. 2001. Use of the preconditioned conjugate gradient algorithm as a generic solver for mixedmodel equations in animal breeding applications. J. Anim. Sci. 79:1166-1172. https://doi.org/10.2527/2001.7951166x.

Vandenplas, J., F. G. Colinet, and N. Gengler. 2014. Unified method to integrate and blend several, potentially related, sources of information for genetic evaluation. Genet. Sel. Evol. 46:59 https://doi .org/10.1186/s12711-014-0059-3.
Vandenplas, J., and N. Gengler. 2012. Comparison and improvements of different Bayesian procedures to integrate external information into genetic evaluations. J. Dairy Sci. 95:1513-1526. https://doi .org/10.3168/jds.2011-4322.

Vandenplas, J., M. Spehar, K. Potocnik, N. Gengler, and G. Gorjanc. 2017. National single-step genomic method that integrates multinational genomic information. J. Dairy Sci. 100:465-478. https:// doi.org/10.3168/jds.2016-11733.

VanRaden, P. M. 2005. Inbreeding adjustments and effects on genetic trend estimates. Interbull Bull. 33:81-84.

VanRaden, P. M. 2008. Efficient methods to compute genomic predictions. J. Dairy Sci. 91:4414-4423. https://doi.org/10.3168/jds .2007-0980.

VanRaden, P. M. 2012. Avoiding bias from genomic pre-selection in converting daughter information across countries. Interbull Bull. 45:29-33.

VanRaden, P. M. 2016. Practical implications for genetic modeling in the genomics era. J. Dairy Sci. 99:2405-2412. https://doi.org/10 $.3168 /$ jds.2015-10038.

VanRaden, P. M., M. E. Tooker, J. B. Cole, G. R. Wiggans, and J. H. Megonigal Jr.. 2007. Genetic evaluations for mixed-breed populations. J. Dairy Sci. 90:2434-2441. https://doi.org/10.3168/ jds.2006-704.

VanRaden, P. M., M. E. Tooker, J. R. Wright, C. Sun, and J. L. Hutchison. 2014. Comparison of single-trait to multi-trait national evaluations for yield, health, and fertility. J. Dairy Sci. 97:79527962. https://doi.org/10.3168/jds.2014-8489.

VanRaden, P. M., C. P. Van Tassell, G. R. Wiggans, T. S. Sonstegard, R. D. Schnabel, J. F. Taylor, and F. S. Schenkel. 2009. Invited review: Reliability of genomic predictions for North American Holstein bulls. J. Dairy Sci. 92:16-24. https://doi.org/10.3168/jds .2008-1514.

VanRaden, P. M., and G. R. Wiggans. 1991. Derivation, calculation, and use of national animal model information. J. Dairy Sci. 74:2737-2746. https://doi.org/10.3168/jds.S0022-0302(91)78453 -1 .

Wiggans, G. R., J. B. Cole, S. M. Hubbard, and T. S. Sonstegard. 2017. Genomic selection in dairy cattle: The USDA experience. Annu. Rev. Anim. Biosci. 5:309-327. https://doi.org/10.1146/ annurev-animal-021815-111422.

Wiggans, G. R., T. A. Cooper, P. M. VanRaden, and J. B. Cole. 2011 Technical note: Adjustment of traditional cow evaluations to improve accuracy of genomic predictions. J. Dairy Sci. 94:6188-6193. https://doi.org/10.3168/jds.2011-4481.

Wiggans, G. R., P. M. VanRaden, and T. A. Cooper. 2012. Technical note: Adjustment of all cow evaluations for yield traits to be comparable with bull evaluations. J. Dairy Sci. 95:3444-3447. https:// doi.org/10.3168/jds.2011-5000. 